\title{
Eph Receptors and Ephrins in the Developing Chick Cerebellum: Relationship to Sagittal Patterning and Granule Cell Migration
}

\author{
Sana D. Karam, ${ }^{1}$ Robert C. Burrows, ${ }^{2}$ Cairine Logan, ${ }^{3}$ Simon Koblar, ${ }^{4}$ Elena B. Pasquale,, 5 and Mark Bothwell ${ }^{1}$ \\ Departments of ${ }^{1}$ Physiology and Biophysics and ${ }^{2}$ Radiology, University of Washington, Seattle, Washington 98195 , \\ ${ }^{3}$ Department of Cell Biology and Anatomy, University of Calgary, Calgary, Alberta, T2N 4N1, Canada, ${ }^{4}$ Department of \\ Genetics, University of Adelaide, Adelaide, South Australia, 5005, Australia, and ${ }^{5}$ The Burnham Institute, La Jolla, California \\ 92037
}

Spatiotemporal expression patterns of six members of the Eph gene family (EphA4, EphA3, EphB2, ephrin-B1, ephrin-A2, and ephrin-A5) were characterized immunocytochemically at various stages of chick cerebellar development. EphA4 expression is observed in the cerebellar anlage as early as embryonic day 5 (E5) and continues in the posthatch cerebellum. During the early period of cerebellar development (E3-E8), complementarity is observed between EphA4 and ephrin-A5 expression within the cerebellar-isthmal region. By E8, differential expression of EphA4 in parasagittal Purkinje cell bands is evident, and the expression remains banded in the posthatch cerebellum. Banded expression of the ephrin-A5 ligand complements EphA4 expression during the middle period (E9-E15). During this period, ephrin-A2 and EphA3 are coexpressed in a banded pattern and with variable correlation to EphA4. Variability in the banding expression is observed for EphA4, EphA3, ephrin-A5, and ephrin-A2 across different lobes, and graded complementarity in the expression pattern of EphA3 and ephrin-A5 is observed in the external granular layer between the posterior and anterior lobes. Analysis of Purkinje cell birth date in correlation with Eph-ephrin expression during the middle period reveals that early-born cells express EphA4, whereas late-born cells express ephrin-A5. Finally, EphA4 expression domains are respected by migrating granule cell ribbons, which express both ephrin-B1 and EphB2. These expression patterns suggest multiple roles for the Eph-ephrin system in cerebellar development, including demarcation/enforcement of boundaries of the cerebellar anlage, formation/maintenance of Purkinje cell compartments, and restriction of the early phase of granule cell migration to ribbons.

Key words: Purkinje cell; Eph; ephrin; compartmentation; stripes; bands; BrdU; birth dating; chick; cerebellum; granule cell; raphes; ribbons; migration; development
In mammals and birds, the neurons of the cerebellar cortex and their associated afferent/efferent connections are organized into a series of parasagittal bands (for review, see Voogd et al., 1996). This compartmentation is strikingly apparent in the biochemical heterogeneity of the morphologically homogeneous Purkinje cells. Such heterogeneity has been demonstrated in the developing cerebellar cortex with various markers, including engrailed-2 (En-2), L7/pcp2, calbindin, wnt-1, wnt-3, and several cadherins, and in the adult cerebellar cortex, zebrin (for review, see Hawkes and Mascher, 1995; Herrup and Kuemerle, 1997; Oberdick et al., 1998).

The mechanism of cerebellar compartmentation is poorly understood. Although Mathis et al. (1997) have demonstrated mediolateral restriction of clonally related Purkinje cell populations, studies using X-inactivation mosaics (Baader et al., 1996) and stem cell chimeras (Hawkes et al., 1998) have shown a lack of correlation between Purkinje cell lineage and zebrin compartments. Retroviral studies in the chick have shown two sequential patterns of dispersion for clones derived from the medial cerebellar ventricular zone: mediolateral followed by anteroposterior (Lin and Cepko, 1999).

Studies assessing incorporation of tritiated thymidine or bromodeoxyuridine (BrdU) have revealed a correlation between the birth date of Purkinje cells and their ultimate location within the cerebellar cortex (Feirabend, 1985; Kanemitsu and Kobayashi, 1988; Ozol and Hawkes, 1997). We therefore sought to examine the

Received Dec. 10, 1999; revised May 3, 2000; accepted June 12, 2000.

This work was supported by National Institutes of Health Grant 2 R01 DC02863, Institutional Grant for Neurobiology 5 T32 GM07108, and March of Dimes Grant 6 FY99-339. We thank Dr. Richard Hawkes for review of this manuscript, Patricia Menzel for affinity purification of anti-ephrinA5 antibody, and Lorraine Gibbs and Laura Sugden for technical assistance.

Correspondence should be addressed to M. Bothwell, Department of Physiology and Biophysics, University of Washington, Box 357290, Seattle, Washington, 98195. E-mail: mab@u.washington.edu.

Copyright (c) 2000 Society for Neuroscience $0270-6474 / 00 / 206488-13 \$ 15.00 / 0$ hypothesis that early- and late-born cells become segregated into alternating parasagittal compartments. In the developing avian cerebellum, parasagittal compartmentation is also revealed by the parasagittally distributed migration of granule cell precursors within distinct ribbons (Feirabend, 1990; Arndt et al., 1998; Lin and Cepko, 1998). In the present study, we consider mechanisms that may guide segregation of early- and late-born Purkinje cells into alternating parasagittal compartments and that may guide granule cell precursors to migrate in parasagittally distributed ribbons.

The Eph receptor tyrosine kinases (RTKs) and their ligands have emerged as molecules that guide migration of cells and axonal growth cones during development, usually via chemorepulsive cell-cell-mediated interaction (for review, see Flanagan and Vanderhaeghen, 1998). There are 14 known receptors and eight ligands. The ligands are membrane bound and subdivided into two groups based on their membrane anchorage: ephrin-A (GPIlinked) and ephrin-B (transmembrane). Ephrin B ligands bind preferentially to EphB receptors, whereas the ephrin A ligands bind preferentially to EphA receptors (Gale et al., 1996). EphA4, however, crosses subclasses by exhibiting appreciable affinity for ephrin-B2, ephrin-B3 (Gale et al., 1996), and, in chicks, ephrin-B1 (E. B. Pasquale, unpublished observations). Perturbation experiments have revealed that EphA4 plays an important role in maintaining well defined boundaries between separate anatomical compartments in the developing forebrain, rhombomeres, and somites, possibly by inhibiting the mixing of cells from different compartments (Xu et al., 1995, 1996, 1999; Durbin et al., 1998, 2000; Mellitzer et al., 1999).

This study examines whether the spatiotemporal expression pattern of Eph receptors and their cognate ephrins is consistent with a role in guiding cell migration to parasagittally organize Purkinje cell subpopulations and cause migration of granule cells at distinct parasagittal positions. 


\section{MATERIALS AND METHODS}

Animals and tissue preparation. Fertile eggs from hens were incubated to the desired developmental age at $38^{\circ} \mathrm{C}$ and $65 \%$ humidity in a forced air incubator. At the time of kill, the embryos were staged (Hamburger and Hamilton, 1951), and the brain was isolated. In embryos older than embryonic day 10 (E10), the hindbrain-cerebellar region was further dissected. The tissue was fixed at room temperature in $70 \%$ ethanol, $20 \%$ formaldehyde, and $10 \%$ acetic acid for a period varying between $1 \mathrm{~min}$ at $\mathrm{E} 3$ and $30 \mathrm{~min}$ at postnatal day 7 (P7).

Antibodies. The following affinity-purified rabbit polyclonal antibodies were used: (1) anti-EphA4 antibody recognizing the $11 \mathrm{C}$-terminal amino acids of the chick EphA4 receptor; (2) anti-EphB2 antibody raised against the antigen comprising amino acids 167-995 of chick EphB2, corresponding to the most extracellular domain, the entire transmembrane, and catalytic domains of the protein; (3) anti-ephrin-B1 antibody made to the entire extracellular domain of the chick ephrin-B1 expressed as an Fc fusion protein in eukaryotic cells; (4) anti-ephrin-A5 made using an ephrin-A5 IgG chimera; and (5) anti-EphA3 antibody recognizing the 12 amino acids at the $\mathrm{C}$-terminal end of the chick EphA3 receptor (Soans et al., 1994). Lack of cross-reactivity with other Eph receptors has been demonstrated for the EphB2, EphA4, and EphA3 antibodies (Pasquale, 1991; Soans et al., 1994; Holash and Pasquale, 1995; Martone et al., 1997; Monschau et al. 1997; Connor et al., 1998). Specificity of both the ephrin-B1 and ephrin-A5 antibodies has also been verified (data not shown; E. B. Pasquale, unpublished observations). All of the Eph-ephrin antibodies with the exception of ephrin-A5 were used at a concentration of $1 \mu \mathrm{g} / \mathrm{ml}$ on tissue sections and $0.5 \mu \mathrm{g} / \mathrm{ml}$ on whole mounts. A $5 \mu \mathrm{g} / \mathrm{ml}$ concentration of the ephrin-A5 antibody was needed, however, to detect a signal on the cerebellar Purkinje cells on tissue sections, although the signal in positive control tissue (caudal tectum) was detected at $1 \mu \mathrm{g} / \mathrm{ml}$.

The following mouse monoclonal antibodies were used: anti-ephrin-A2 (kindly provided by Uwe Drescher, Max-Planck Institute for Developmental Biology, Tubingen, Germany) (Hornberger et al., 1999), anti-calbindin$\mathrm{D}_{28 \mathrm{~K}}$ (Sigma, St. Louis, MO), anti-BrdU, and anti-Pax6 (Developmental Studies Hybridoma Bank, University of Iowa, Department of Biological Sciences, Iowa City, IA). For single peroxidase labeling of the EphA4, EphA3, or eprhin-A5 antibodies, biotinylated goat anti-rabbit IgG (Vector Laboratories, Burlingame, CA) followed by streptavidin HRP (Zymed Laboratories, San Francisco, CA) were visualized with 3,3'-diaminobenzidine (DAB) as the chromagen (Sigma). For double fluorescent labeling, the EphA4, the EphB2, and the ephrin-B1 antibodies were detected using a donkey anti-rabbit indocarbocyanine dye (Cy3) (Jackson Laboratories, West Grove, PA), whereas ephrin-A2, BrdU, calbindin, and Pax6 were detected using biotinylated horse anti-mouse IgG (Vector Laboratories) followed by avidin-conjugated to FITC (Vector Laboratories).

Immunostaining. After the tissue was fixed, dehydrated, and embedded in paraffin, transverse, horizontal, and sagittal sections of $8-12 \mu \mathrm{m}$ thickness were cut and mounted on gelatin/poly-L-lysine-coated slides. After dewaxing and rehydration, the slides were subjected to an antigen retrieval protocol consisting of immersion in 1\% SDS in PBS for $5 \mathrm{~min}$. After thorough washes in PBS, the sections to be visualized with DAB were incubated for $10 \mathrm{~min}$ in $100 \%$ methanol with $0.3 \%$ hydrogen peroxide to block endogenous peroxidase activity. To reduce nonspecific background staining, the slides were incubated for $20 \mathrm{~min}$ in $0.1 \mathrm{M}$ glycine, $\mathrm{pH} 7.3$, with Tris base. Sections were then incubated for $1 \mathrm{hr}$ at room temperature in blocking solution $[5 \%$ skim milk, $0.2 \%$ Triton X-100 in Tris-buffered saline (TBS)] followed by sequential incubation in primary and secondary antibodies, appropriately diluted in blocking solution. Primary, biotinylatedsecondary, and avidin-conjugated antibodies were incubated at room temperature in a moist chamber overnight for 90 and $60 \mathrm{~min}$, respectively. After visualization of peroxidase labeled sections with DAB, slides were dehydrated in ethanol, coverslipped with DPX (Electron Microscopy Sciences, Ft. Washington, PA), and viewed under a Nikon Eclipse E400 microscope (Nikon Inc., Melville, NY). For double-label immunofluorescence, the donkey anti-rabbit $\mathrm{Cy} 3$ and the horse anti-mouse biotinylated $\mathrm{IgG}$ were applied simultaneously and incubated for $90 \mathrm{~min}$ at room temperature, followed by the application of avidin FITC for $60 \mathrm{~min}$. Sections were mounted with Vectashield (Vector Laboratories), then analyzed and digitized with a confocal microscope (Bio-Rad Laboratories, Hercules, CA). Using Photoshop (Adobe, Mountain View, CA) and Powerpoint (Microsoft, Seattle, WA), the images were cropped and corrected for brightness and contrast but were not otherwise modified. For DAB stained sections, photographic images were scanned with a Nikon slide scanner and contrast-enhanced using Photoshop.

For immunostaining of frozen sections, heads of chicken embryos were fixed in $4 \%$ paraformaldehyde for $3 \mathrm{hr}$ at $4^{\circ} \mathrm{C}$, then cryoprotected through a graded series of sucrose $(10-30 \%)$ in PBS. Tissue was embedded in Tissue Tek O.C.T. medium (Miles, Elkhardt, IN) and frozen in liquid nitrogen, and $20 \mu \mathrm{m}$ cryostat sections were collected on gelatin/poly-Llysine-coated slides. With the exception of antigen retrieval, the immunostaining protocol was similar to the one described above for paraffin sections. The procedure for whole-mount immunostaining was adopted from Arndt and Redies (1998).

BrdU labeling. For labeling late-born cells, embryos were pulsed between $\mathrm{HH} 28$ and HH29 with $500 \mu \mathrm{g}$ of BrdU (Sigma) per gram of body weight applied to the chorioallantoic membrane (Tanaka et al., 1996). To calculate the BrdU dosage, the average weight of six staged embryos was taken before each pulsing. For labeling of early-born cells, HH23 embryos were pulsed with $62.5 \mu \mathrm{g}$ of BrdU per gram of body weight. After application of BrdU, the embryos were returned to the incubator until E11, at which point they were staged and killed for immunocytochemical analysis. For BrdU immunostaining, sections were treated with $2 \mathrm{~N}$ hydrochloric acid ( $\mathrm{HCl}$ ) with $0.2 \%$ Triton $\mathrm{X}-100$ in TBS for $30 \mathrm{~min}$ at $37^{\circ} \mathrm{C}$ followed by a 5 min wash in borate buffer, $\mathrm{pH}$ 8.5. In double immunofluorescence staining, this treatment occasionally resulted in mild diminution of the EphA4 signal and a decreased signal-to-background ratio (see Fig. 9H). Thirty embryos were used for analyzing the localization of late-born cells, and 15 were used for the analysis of early-born cells.

\section{RESULTS}

The data are organized into early period (E3-E8), middle period (E9-E15), and late period (E15 onward) stages of chick cerebellar development, delineated in Feirabend (1990). The first $3 \mathrm{~d}$ of the early period mark the birth dates of Purkinje cells and cells of the deep nuclei. From E5 onward, Purkinje cells migrate to the mantle layer, and by the end of the early period (E8), morphological clustering of future Purkinje cells in a longitudinally banded pattern becomes apparent (Feirabend, 1990). During the middle period of cerebellar development, granule cell precursors start migrating inwardly as narrow ribbons from the external granular layer (EGL) through the primitive molecular layer to the future inner granular layer. The late period of cerebellar development begins near the end of E15, when massive migration of granule cell precursors begins. During this period, migrating granule cell precursors filter through the Purkinje cell layer without regard to the position of Purkinje cell compartmental boundaries. The results of the current study are based on immunocytochemical observations in the horizontal, coronal, and sagittal planes of at least five animals per stage.

\section{Early period}

EphA4 expression in the cerebellar anlage in the early period is illustrated in a lateral sagittal section of a stage 27 (E5) chick embryo (Fig. 1A). Although the boundaries of the cerebellar anlage are not precisely known, the pattern of EphA4 expression at this stage suggests that it may play a role in either defining the boundaries of the cerebellar anlage or defining boundaries within the cerebellar anlage. EphA4 is expressed in a caudal to rostral gradient in the cerebellar anlage, with the highest level of expression caudally at the tip of the medullary velum (Fig. $1 A$ ). The posterior tectum and most of the isthmal region (Altman and Bayer, 1995) appear devoid of EphA4 (Fig. 1A), except for a narrow region within the isthmus (Fig. $1 C, E$ ). Interestingly, a reciprocal pattern of expression is observed for the ligand ephrin-A5 (Fig. 1B,D). Ephrin-A5 is present in the caudal tectum and the isthmal region, diminishing toward the anterior border of the cerebellar anlage (Fig. $1 B$ ). The complementary expression of EphA4 and ephrin-A5 along the anterior-posterior axis continues throughout the early period of cerebellar development (Fig. 1E,F). Transitions between EphA4- and ephrin-A5-expressing domains define three distinct boundaries within the cerebellar anlage and the isthmus (Fig. 1B,D,F, arrowheads). Such boundaries in the vicinity of the presumed rostral and caudal limits of the cerebellar anlage may define the limits of this compartment.

By stage 27 (E5), EphA4 expression in the cerebellar anlage extends into the newly formed mantle zone, which consists of a cell-dense region bordering the ventricular zone (Fig. 2A). A transverse section of a stage 27 (E5) cerebellum shows that the mantle layer contains two regions of EphA4-positive cells, one at the inner part of the mantle layer bordering the EphA4 positive ventricular zone and the other adjacent to the pial surface of the cerebellum (Fig. 2A). These two regions appear to correspond to the medial domain (MD) and lateral domain (LD) of cadherin expression reported by Arndt and Redies (1998). Separating MD and LD is a fiber tract that strongly expresses EphA4 (Fig. 2A,C). The fibrous nature of this tract was verified with Tau immunostaining (Fig. 1C,D).

EphA4 expression at stage 29 (E6) is similar to the preceding stage except that the expression has diminished in the ventricular 


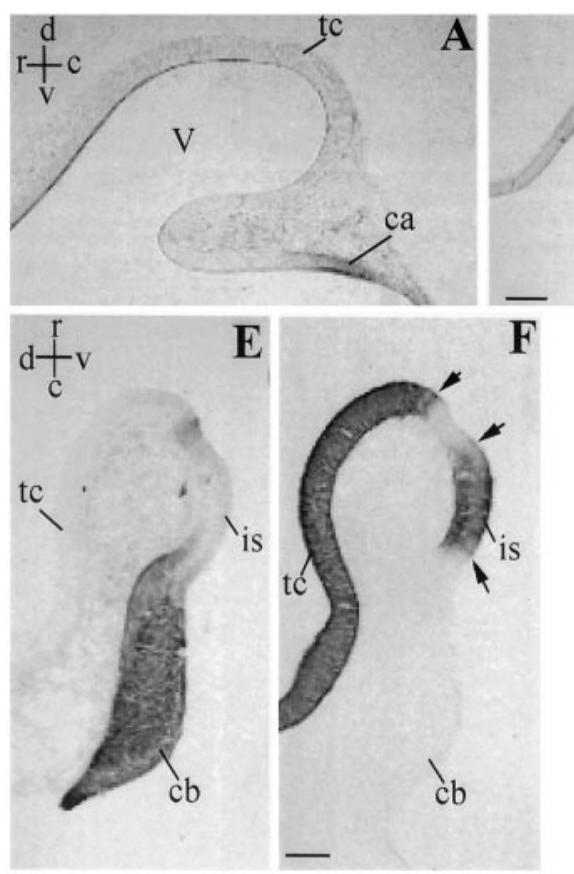

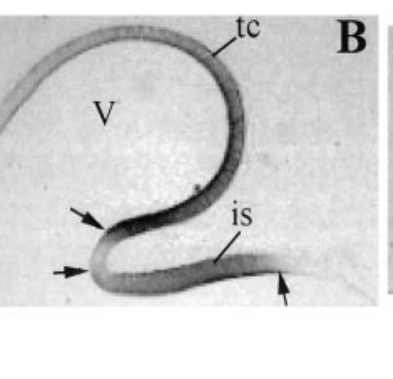
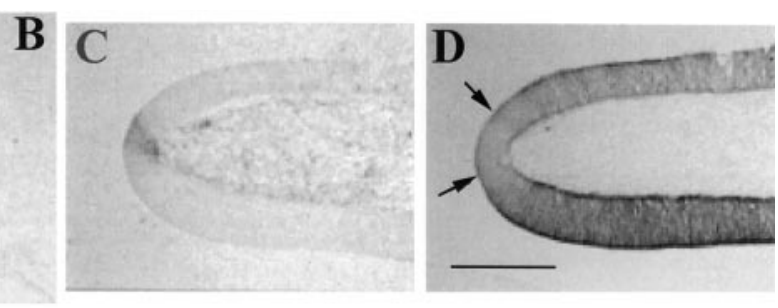

Figure 1. Complementary immunostaining of EphA4 $(A, C, E)$ and ephrin-A5 $(B, D, F)$ in sagittal frozen sections at stage $27(\mathrm{E} 5)(A-D)$ and stage $32(\mathrm{E} 7)(E, F)$. Arrowheads in $B, D$, and $F$ point to the boundaries of reciprocal EphA4-ephrin-A5 expression within the cerebellar and isthmal regions. Sections in $A, C$, and $E$ are adjacent to those in $B, D$, and $F$. $C, D$, High magnification of the isthmal region from sections lateral to $A$ and $B$ showing the complementarity of staining within the isthmal region. $c a$, Cerebellar anlage; $c b$, cerebellum; $i s$, isthmus; $t c$, tectum; $V$, ventricle. Scale bars, $200 \mu \mathrm{m}$.

neuroepithelium (Fig. 2E). Feirabend (1990) has identified the superficial part of the mantle layer as the future external granular layer. This region is devoid of EphA4 expression (Fig. 2E, egl), as is the external granule layer at later developmental stages. Figure $2 G$ shows extensive EphA4 expression in the caudal cerebellum at stage 28, with the exception of the ventricular neuroepithelium, which is devoid of EphA4 immunoreactivity.

Figure $3 A$ shows EphA4 expression in a transverse section at stage 31 (E7). At this stage, the MD appears as a wide band, with a lower level of EphA4 expression closer to the ventricular zone (Fig. 3A, asterisks). At stage 34 (E8), EphA4 expression becomes restricted to a series of parasagittal bands (Fig. $3 B$ ). Differential EphA4 expression is observed in the inner cortical-future Purkinje cell-layer (Fig. 3B). Cells of the deep cerebellar nuclei, as well as the fiber tracts connecting them to the Purkinje cells, also show EphA4 expression (Fig. $3 B$ ). The external granular layer appears devoid of EphA4 expression (Fig. 3B).

\section{Middle period}

During the middle period (E9-E15), EphA4 expression continues in cells of the deep cerebellar nuclei (Fig. 3D) and in parasagittal bands of Purkinje cells (Figs. 3-10). EphA4 immunostaining in the Purkinje cell layer appears localized to the surface of Purkinje cell soma (see Fig. 5). For each lobule, the EphA4-positive and EphA4negative bands have been alphabetically labeled in a sequential manner from the midline, as shown in Figures $3 D, 4 A, B, 5 A, B$, $6 B-F, 7,9$, and $10 B$. The number and the width of these bands vary among lobules, as do the level and uniformity of expression within a certain band (Figs. $4 A, 6 B, D, F, 7,9,10 B$, Table 1). Generally, EphA4 is present in bands $\mathrm{B}$ and $\mathrm{D}$, absent in bands $\mathrm{C}$ and $\mathrm{E}$, and expressed variably in band $\mathrm{A}$ in different lobules (Figs. $4 A, 6 B, D, F$, $7,9,10 B)$. A detailed description of this distribution is provided in Table 1. Both the lack of parasagittal band contiguity and the alteration in the levels of EphA4 band expression among the different lobules are evident in a sagittal section of an E11 cerebellum (Fig. 3C). The pattern of expression of EphA4 protein in the middle period is consistent with the pattern of EphA4 mRNA expression reported by Lin and Cepko (1998).

To verify that EphA4 is differentially expressed within Purkinje cell parasagittal domains, we used immunofluorescent localization of calbindin, a Purkinje cell marker. Although calbindin and EphA4 are extensively coexpressed (Figs. $5 C, D$ ), the expression of calbindin in band $\mathrm{C}$ confirms that this EphA4-negative band indeed contains Purkinje cells (Fig. 5A,B).
Ephrin-A5, which displays high affinity for EphA4 (Gale et al., 1996), is expressed in Purkinje cell bands corresponding to EphA4negative regions. No ephrin-A5 expression is observed in lobule IX (Fig. 4D), but ephrin-A5 expression is present on Purkinje cells in bands $\mathrm{C}$ and $\mathrm{E}$ in lobule VIII and rostrally (Figs. 4D, 6, 8B). In band $\mathrm{A}$ of central lobules, ephrin-A5 is expressed in a pattern that is complementary to the distribution of EphA4 in band A (Figs. $4 D, 6 C-F)$. Table 1 provides more detail on this pattern of distribution. In general, ephrin-A5 immunoreactivity appears highest anteriorly, where the protein also seems to be localized on cells of the proliferative external granular cell layer (Figs. 6C,E, 8D). Ephrin-A5 expression is also present on cells of deep cerebellar nuclei (data not shown).

Ephrin-A2, another ligand known to bind EphA4 (Gale et al., 1996), also is expressed in a parasagittally banded pattern at stage 36 (E10), as demonstrated by whole-mount immunostaining (Fig. $4 G, H)$. Ephrin-A2 protein expression is localized to the Purkinje cell layer and to deep cerebellar nuclei (Fig. 7). The distribution of ephrin-A2 relative to that of EphA4 is complex (Fig. 7, Table 1). In some lobules, ephrin-A2 is extensively coexpressed with EphA4 (Fig. 7A-C, Table 1). However, ephrin-A2 is expressed heterogeneously within some bands, in gradients that are complementary to those displayed by EphA4 [Fig. 7 (and summarized in Table 1)]. The levels of ephrin-A2 immunostaining are higher in anterior lobules, where the graded complementarity of ephrin-A2-EphA4 expression is also evident in the medial cerebellar nuclei (Fig. $7 P-R$; data not shown).

Because areas of colocalization were observed between EphA4 and eprhin-A2, we examined the expression of another Eph receptor, EphA3, which has been shown to bind ephrin-A2 (Cheng and Flanagan, 1994; Monschau et al., 1997). Like EphA4, ephrin-A2, and ephrin-A5, EphA3 displayed a lobe-dependent variability in its expression pattern (Figs. $4 E, F, 8 A, E$ ). Although the anterior lobe was devoid of EphA3 expression, banded EphA3 expression on Purkinje cells was observed centrally (lobules VII-VI). This banded pattern shows a large degree of similarity to that of ephrin-A2 (Fig. 4E-H, Table 1). A representative section is shown in Figure $8 A$. The expression in posterior lobules (X-VIII) is homogeneous and diffuse (Figs. $4 E, 8 E$ ) and appears most prominently in the EGL (Fig. $8 E, F$ ). Along the anterior to posterior axis, this EGL expression complements that of ephrin-A5, as shown in a parasagittal plane of section in Figure $8 C, D$.

Previous studies have suggested a correlation between Purkinje 

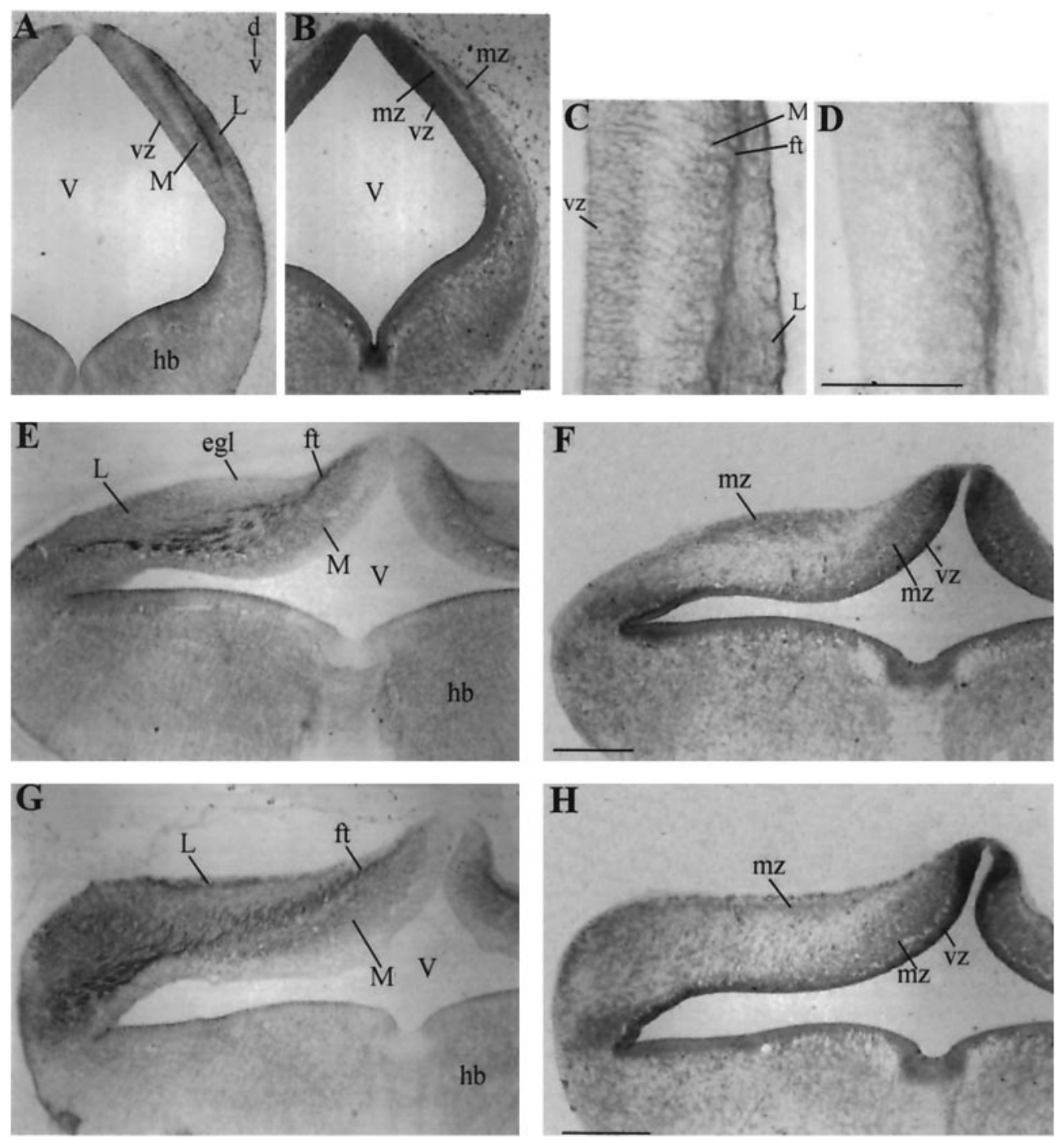

Figure 2. EphA4 immunostaining in paraffin sections at various stages of early cerebellar development. $A$, Transverse section of a cerebellum at stage 27 (E5) with an adjacent nissl stain in $B$. Note EphA4 expression in the ventricular zone $(v z)$, in the medial $(M)$ and lateral $(L)$ subdivisions of the mantle zone, and on a fiber tract $(f t)$ separating the medial and lateral subdivisions. $C$, High magnification of the cerebellar anlage in $A$ with an adjacent Tau staining in $D$ showing the fibrous nature of the tract separating the medial and lateral subdivisions. $E$, Transverse section of stage 29 (E6) cerebellum with an adjacent niss] stain in $F$. The expression is similar to stage 27 except for downregulation in the $v z$ and an area in the cerebellum that is devoid of EphA4 expression $(E, e g l) . G$, Transverse section through the caudal cerebellum at stage 29 (E6) with adjacent nissl stain in $H$. EphA4 expression appears more extensive in caudal sections as compared with rostral sections $(E)$. egl, Future external granule cell layer as defined by Feirabend (1990); $f t$, fiber tract; $h b$, hindbrain; $m z$, mantle zone; $M$, medial subdivision; $L$, lateral subdivision; $V$, ventricle; $v z$, ventricular zone. Scale bars, $200 \mu \mathrm{m}$. cell birth date and their final parasagittal distribution (Feirabend et al., 1985; Kanemitsu and Kobayashi, 1988; Ozol and Hawkes, 1997). To investigate the relationship between EphA4 expression and Purkinje cell birth date during the middle period of cerebellar development, embryos were pulsed with BrdU between stages 28 (E5.5) and 29 (E6) to label Purkinje cells born during the latter period of Purkinje cell genesis (Feirabend et al., 1985), then killed at stage 37 (E11) for double immunostaining of BrdU and EphA4. To label early-born cells, embryos were pulsed at stage 23 (E3) with a much lower dose of BrdU (see Materials and Methods). Because there is a posterior to anterior gradient of development in the cerebellum, labeling with BrdU at stage 28-29 in some cases resulted in labeling of granule cells in posterior lobules, since the EGL also starts proliferating in a posterior to anterior gradient.

Our results confirm that early- and late-born cells segregate differentially into Purkinje cell parasagittal domains, revealing a substantial correlation between birth date and Eph-ephrin phenotype. In all 30 cases analyzed, late-born Purkinje cells localize in bands $\mathrm{C}$ and $\mathrm{E}$ and to all of band $\mathrm{A}$ (posteriorly) or the medial portion of band A centrally (Fig. 9A-O). Conversely, early-born cells localize in bands $\mathrm{B}$ and $\mathrm{D}$ (Fig. $9 P-R$ ). Thus, late-born cells localized within band A would express ephrin-A2 (in all lobules) and ephrin-A5 (centrally and anteriorly). Late-born cells localized within bands $\mathrm{C}$ and $\mathrm{E}$ would express ephrin-A5. The observation that late-born cells do not express EphA4 is consistent with the downregulation of EphA4 in the ventricular zone after E5 (Fig. $2 E)$. Conversely, the conclusion that late-born cells express ephrin-A5 is consistent with the appearance of ephrin-A5 in the cerebellum only after E5.5 (data not shown).
The middle period of cerebellar development marks the start of granule cell migration in a pattern that has been described as granule cell raphes (Feirabend, 1990; Lin and Cepko, 1998) or granule cell ribbons (Arndt et al., 1998). To investigate the relationship between EphA4-positive Purkinje cell segments and the migrating granule cell ribbons, we performed immunofluorescent localization of EphA4 and Pax6, a granule cell marker (Lin and Cepko, 1998) (Fig. $10 A-C$ ). Thin ribbons of Pax6-positive granule cells, serially numbered from the midline, migrate radially at the boundaries of compartments defined by the differential expression of EphA4 (Fig. 10 $A-C$ ).

Pasquale et al. (1992) previously reported the expression of EphB2 in the premigratory zone of the external granular layer, in the parallel fibers, and on cell bodies of migrating granule cells. Figure $10 G-I$ confirms their findings and further demonstrates expression in granule cell ribbons. Cells within these ribbons appear to downregulate EphB2 expression as they enter the internal granule cell layer. Ephrin-B1, a ligand for EphB2, is expressed on the migrating granule cell ribbons beginning at E9, which marks the start of ribbon formation (Fig. $10 D-F$ ).

Because members of the ephrin-B subfamily are reported to be expressed on cerebellar glial cells in rodents (Wagner and Arenas, 1998), we localized ephrin-B1 and the granule cell marker, Pax6, on the same tissue sections to verify the neuronal nature of ephrin-B1 expression (Fig. 10D-F). Ephrin-B1 expression is lacking in the proliferative zone of the external granule cell layer, but it is observed in the premigratory zone (Fig. 10E). The migrating granule cell ribbons and their extensions, the parallel fibers, also express ephrin-B1 (Fig. 10E,F). Double immunostaining with the 

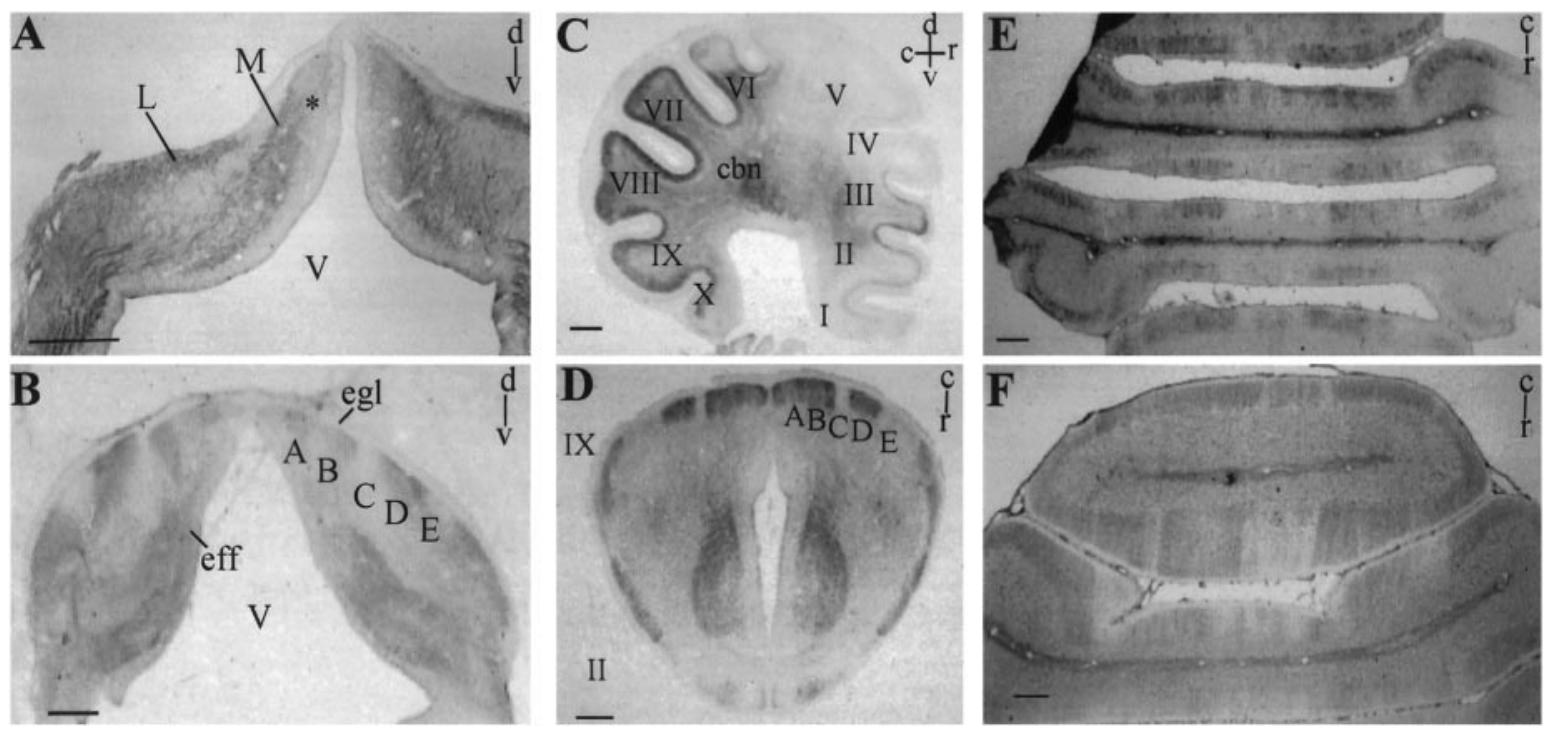

Figure 3. EphA4 immunostaining in transverse $(A, B)$, coronal $(D-F)$, and sagittal $(C)$ paraffin sections at stages $31(\mathrm{E} 7, A), 34(\mathrm{E} 8, B), 37(\mathrm{E} 11, C, D)$, $45(\mathrm{E} 20, E)$, and P7 $(F)$. Parasagittal banded EphA4 expression is apparent at E8 $(B)$ and persists to posthatch $(F)$. Asterisk in $A$ refers to the segment with the lower level of EphA4 expression. Roman numerals refer to cerebellar lobules. $A-E$ in $B$ and $C$ refer to Purkinje cell parasagittal bands labeled alphabetically from the midline. $c b n$, Deep cerebellar nuclei; $c c$, ventral cerebellar commissure; eff, corticonuclear efferents; egl, external granular layer; $L$, lateral subdivision; $M$, medial subdivision; $V$, ventricle. Scale bar, $200 \mu \mathrm{m}$.

radial glial marker vimentin and ephrin-B1 at this age demonstrated a lack of ephrin-B1 expression on glial cells and further supports the neuronal nature of ephrin-B1 expression (Fig. 10L). Finally, in posterior regions of the cerebellum, EphA3 expression is observed on the migrating granule cell ribbons and on parallel fibers (Fig. 8F).

\section{Late period}

The late period of cerebellar development begins at E16 with massive migration of granule cells and disappearance of granule cell ribbons (Feirabend, 1990). Differential EphA4 expression in Purkinje cell bands continues throughout this period of cerebellar development. Figure 3, $E$ and $F$, shows EphA4 expression within Purkinje cell parasagittal bands in the E20 (stage 45) and P7 cerebellum. At least in lobules I-VI, the banded pattern of expression in the Purkinje cell layer continues until at least P8 (data not shown). EphA4 expression appears to be localized to the Purkinje cell bodies and their terminal dendrites (Fig. $3 E, F$ ). The expression of EphA3, ephrin-A2, and ephrin-A5 also continues on Purkinje cells during this period (data not shown). Expression of EphB2 and ephrin-B1 also continues throughout this period on parallel fibers in the molecular layer (Fig. 10J,K). A lower level of ephrin-B1 and EphB2 expression is also seen on cell bodies of granule cells in the internal granule cell layer (Fig. 10J,K). By hatch date, EphB2 and ephrin-B1 expression is restricted to the parallel fibers of the molecular layer (data not shown).

\section{DISCUSSION}

Our analysis of the spatiotemporal expression patterns of various Eph and ephrin proteins in developing chick cerebellum suggests that the Eph-ephrin signaling system participates in cerebellar compartmentation. The patterns of expression that we have described are consistent with a potential role for the Eph receptors and ephrins in four developmental processes: (1) establishment and/or stabilization of boundaries of the cerebellar anlage; (2) restriction of Purkinje cell migration resulting in biochemically specialized parasagittal domains of Purkinje cells; (3) restriction of the early phase of granule cell migration to ribbons at the boundaries between biochemically specialized domains of Purkinje cells; and (4) regulation of axon pathfinding for afferent and efferent cerebellar pathways.

\section{Early boundaries within the cerebellar-isthmal region}

The remarkable complementarity of expression of the receptor EphA4 and the ligand ephrin-A5 in the early period of cerebellar development biochemically defines three distinct boundaries within the isthmal brain region and the cerebellar anlage (Fig. $1 B, D$, arrows). This pattern is reminiscent of the contemporaneous complementary distribution pattern of Ephs and ephrins in the rhombomeres, where repulsive interactions between cells expressing EphA4 and cells expressing cognate ephrins enforce the boundary between rhombomeric compartments (Xu et al., 1995, 1999). Similar roles in maintenance of tissue compartmental boundaries have been suggested for other systems exhibiting complementary patterns of expression of Ephs and ephrins (Gale et al., 1996, Durbin et al., 2000). Perhaps, therefore, EphA4 and ephrin-A5 may similarly contribute to defining boundaries separating compartments with differing developmental fates in the vicinity of the cerebellar anlage. In light of the imperfect fate-mapping of this region, however, it is unclear whether the boundaries in question delimit the cerebellar anlage (for example, by defining the boundary between cerebellum and isthmus) or whether they define subcompartments within the cerebellar anlage itself. Further experiments using recently described markers of the anlage (Millet and Alvarado-Mallart, 1995; Wingate and Hatten, 1999) should permit this question to be resolved.

\section{Formation and maintenance of parasagittal Purkinje cell compartments}

Our results demonstrate that EphA3, EphA4, ephrin A-2, and ephrin-A5 are expressed in parasagittally banded patterns in Purkinje cells (Figs. 4, 6, 7, 8, 9). We have considered three mechanisms for production of the parasagittally banded distribution of distinct Purkinje cell populations.

\section{Mechanism 1}

Banded subdomains may exist within the cerebellar ventricular zone, with different Purkinje cell subpopulations arising within distinct ventricular zone subdomains and migrating without mixing of cells from different subdomains.

\section{Mechanism 2}

A homogeneous population of Purkinje cell precursors emerging from the ventricular zone might differentiate during migration into 

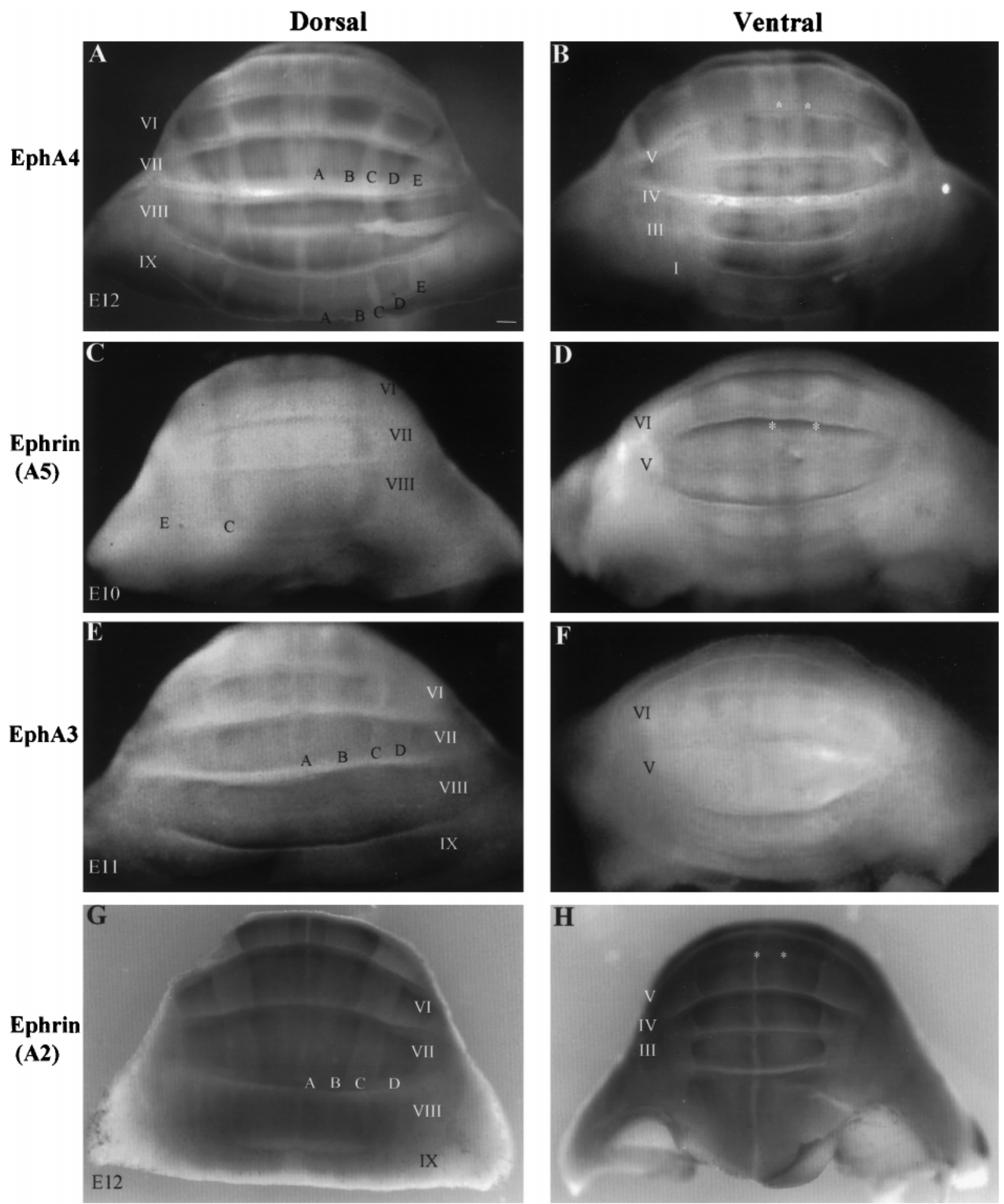

Figure 4. Dorsal and ventral views of EphA4 $(A, B)$, ephrin-A5 $(C, D)$, EphA3 $(E, F)$, and ephrin-A2 $(G, H)$ whole-mount immunostaining on chick cerebella taken between stages 36 (E10) and 38 (E12). A, B, C,D, and $E$ refer to Purkinje cell domains labeled alphabetically from the midline. Asterisks in $B, D$, and $H$ point to EphA4 staining $(B)$ or its corresponding location $(D, H)$. Roman numerals refer to cerebellar lobules. Scale bar, $200 \mu \mathrm{m}$.

several alternative subtypes based on environmental cues that are distributed in a banded pattern within the mantle zone of immature cerebellar cortex.

\section{Mechanism 3}

Differing environmental cues existing in the ventricular or mantle zone, or both, during the early and late period of Purkinje cell specification might specify two (or more) states of Purkinje cell differentiation, causing migration of Purkinje cells to be guided by repulsive interactions between unlike cells (i.e., early-born vs late- born cells) or attractive interactions between like cells (i.e., earlyborn to early-born and late-born to late-born), resulting in formation of parasagittal bands by a process of cell sorting. Although we cannot exclude Mechanism 1, there is no evidence for the predicted banded heterogeneity within the ventricular zone of the cerebellar anlage. Although Mechanism 2 is plausible, we favor Mechanism 3, which is supported by results from two studies.

First, recent clonal analysis in the developing chick cerebellum revealed no correspondence of Purkinje cell clones to the parasagittal domains of gene expression (Lin and Cepko, 1999). This 

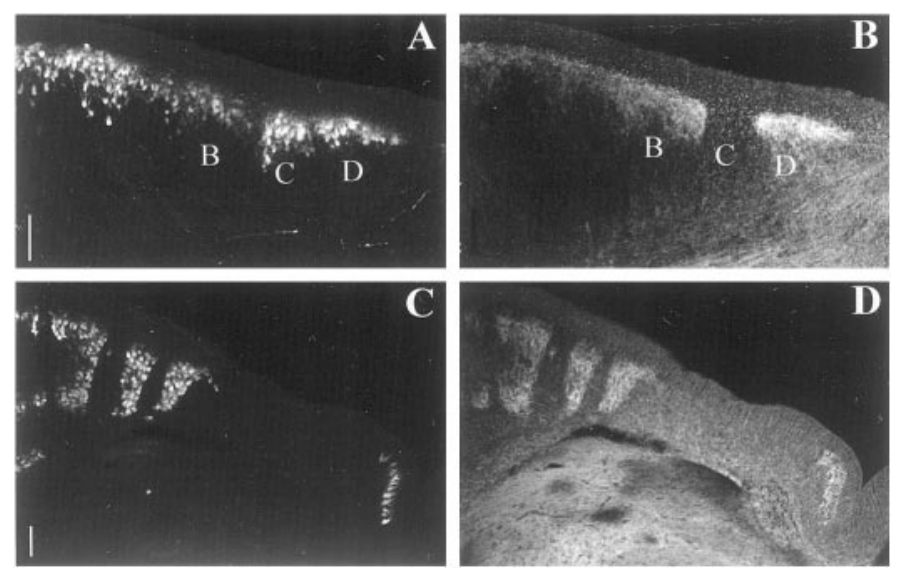

Figure 5. Double immunostaining of EphA4 ( $B$ and $D)$ and calbindin $(A$ and $C$ ) in coronal plane of frozen sections of a stage 40 (E14) cerebellum. $A, B$, Purkinje cell band, $C$, is devoid of EphA4 labeling but is calbindin positive. $C, D$, In most areas, EphA4 and calbindin bands colocalize. $B, C$, and $D$ in $A$ and $B$ refer to Purkinje cell parasagittal bands. Scale bar, $100 \mu \mathrm{m}$.

analysis also revealed a substantial mediolateral dispersion of a subset of cerebellar Purkinje cell clones that seems inconsistent with Mechanism 1 (Lin and Cepko, 1999). Second, data from chick/quail chimera experiments indicate that neighboring Purkinje cells in cortical lobules are not necessarily generated from contiguous progenitors in the ventricular zone, because donor Purkinje cells in cortical lobules were found surmounting the host ventricular zone (Alvarez Otero et al., 1993). Both studies establish that mechanisms exist permitting distinct parasagittally arranged compartments to arise via cell mixing and sorting.

If distinct parasagittal compartments arise by cell sorting, when does this sorting occur? In the chick cerebellum, the Purkinje cells are born on E3, E4, and E5. Parasagittally banded organization, marked biochemically (Chedotal et al., 1996; Arndt and Redies, 1998; Lin and Cepko, 1998; our data) or morphologically by clustering of cells into "corticogenetic zones" (Feirabend, 1990), first becomes apparent shortly after the late-born Purkinje cells migrate from the ventricular neuroepithelium sometime between HH32 (E7.5) and HH34 (E8). No apparent heterogeneity was observed in the ventricular zone during the period in which Purkinje cells and cells of the deep cerebellar nuclei are born (HH22 to HH27) (Fig.
2) (Feirabend et al., 1985). This suggests that parasagittal compartments first arise as late-born Purkinje cells join early-born Purkinje cells in the mantle zone.

Our data provide evidence for a strong correlation between Purkinje cell birth date and Eph-ephrin phenotype (Figs. 6, 7, 9, Table 1). These data suggest a model in which late-born cells are directed to express ephrin-A5 (and ephrin-A2 in band A), earlyborn cells are directed to express EphA4, and repulsive interactions between cells bearing these two proteins either direct the original segregation of cells into distinct coherent groups or enforce the boundaries between parasagittal bands generated by other mechanisms. The more complex pattern of correlation of EphA3 and ephrin-A2 with Purkinje cell birth date leaves open the possibility that they also may contribute to this process. Other Ephs and ephrins not examined in the present study may also contribute. Lin and Cepko (1998) have shown that EphA5 is expressed in parasagittal bands in the cerebellum, in a pattern distinct from EphA4. Other types of proteins also may contribute. Arndt and Redies (1998) demonstrated that developing chick Purkinje cells express various cadherins differentially in parasagittal bands. The expression pattern of cadherin $6 \mathrm{~B}$ appears almost identical to that of EphA4 [compare Fig. $10 B$ in this paper with Fig. $3 B$ in Arndt et al. (1998)]. Thus, homophilic adhesive mechanisms mediated by proteins such as cadherins, as well as active guidance cues mediated by proteins such as those of the Eph-ephrin system, are likely to contribute to the formation and maintenance of distinct parasagittal compartments of Purkinje cells. A comparison between our current observations and earlier published work focusing on parasagittal domains at similar stages in the chick is shown in Table 2. Because we have not replicated the work of others, it is important to emphasize that Table 2 is based solely on visual comparison of individual figures.

If the Eph-ephrin system does contribute to the parasagittal patterning of the developing cerebellum, then it will be important to characterize transcriptional mechanisms that govern the expression of these molecules. In this regard, it is important to note that the engrailed genes are expressed in the developing cerebellum in a parasagittally banded pattern (Millen et al., 1994; Lin and Cepko, 1998). The engrailed gene products have been shown to be regulators of ephrin expression in other systems (Logan et al., 1996) (Table 2). The recent report that misexpression of En-2 in the developing cerebellum causes blurring of the boundaries between
VIII
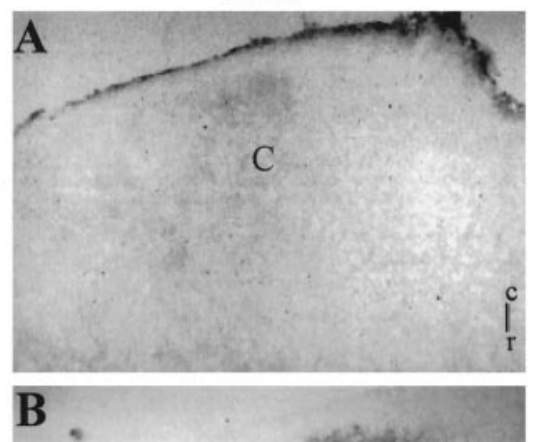

$\operatorname{EphA4}$

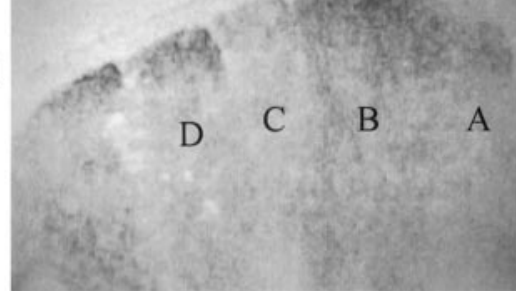

VI
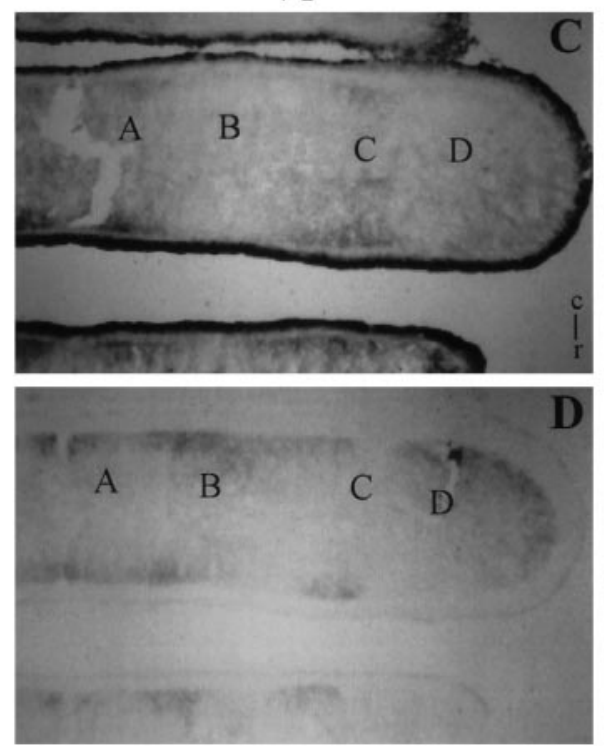
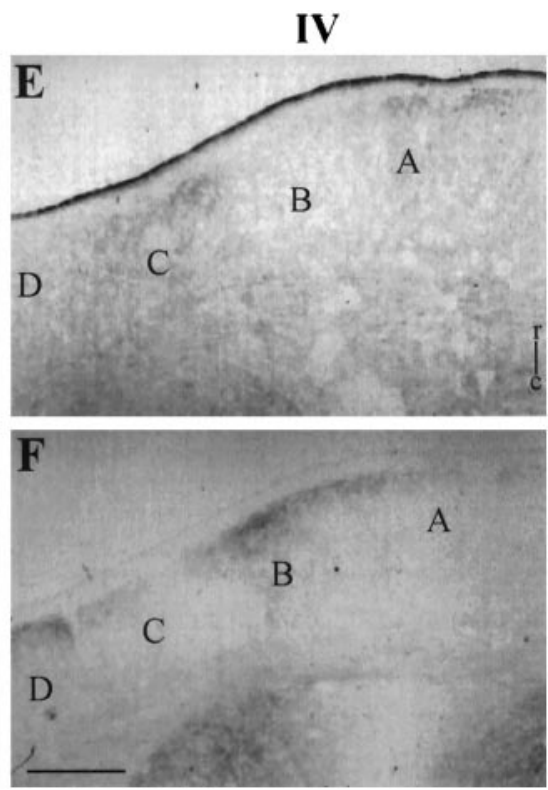

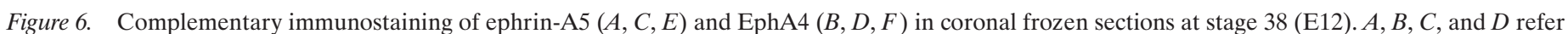
to Purkinje cell domains labeled alphabetically from the midline. Roman numerals refer to cerebellar lobules. Scale bar, 200 m. 


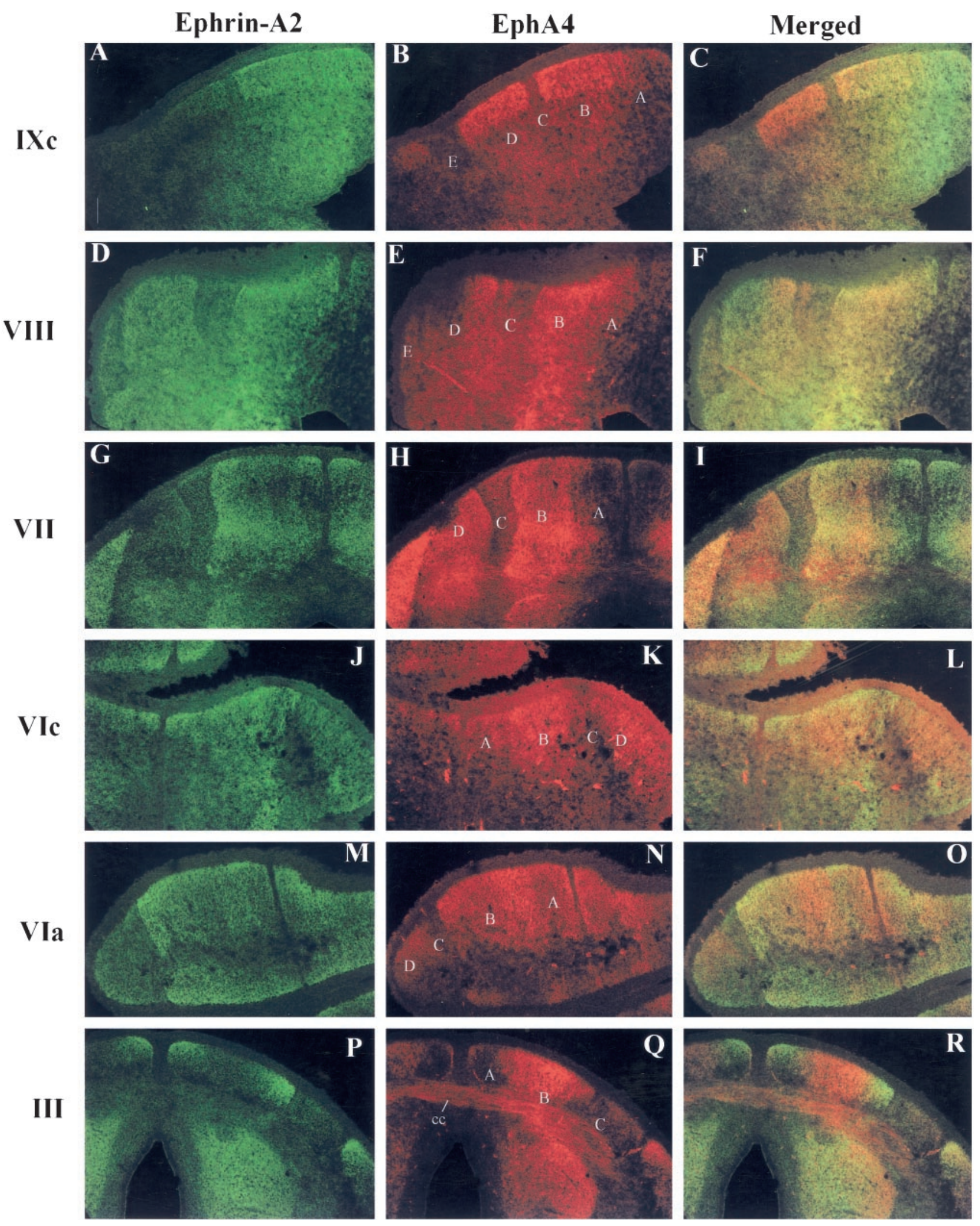

Figure 7. Double immunostaining of EphA4 (red in $B, C, E, F, H, I, K, L, N, O, Q$, and $R$ ) and ephrin-A2 (green in $A, C, D, F, G, I, J, L, M, O, P$, and $R$ ) in coronal plane of frozen sections of a stage 37 (E11) chick cerebellum. Sections in $A-O$ are within $20-40 \mu \mathrm{m}$ from those in Figure 9 . $A, B, C, D$, and $E$ refer to Purkinje cell compartments labeled alphabetically from the midline. Roman numerals refer to cerebellar lobules. $c c$, Cerebellar commissure. Scale bar, $100 \mu \mathrm{m}$.

parasagittal compartments (Baader et al., 1999) is consistent with the predicted results of altered expression of an ephrin.

Finally, the variable pattern of parasagittal stripe expression for the Ephs and ephrins examined (Table 1) across the different lobules suggests that transverse zones exist within the chick cerebellum. In the mouse cerebellum, Rogers et al. (1999) demonstrated the restricted expression of a number of Eph receptors expressed in the Purkinje cell layer across the different lobules. 
Table 1. Distribution patterns of Eph receptors and ephrins within parasagittal domains of Purkinje cells during the middle period of cerebellar development

\begin{tabular}{lllll} 
Zone $/$ lobules & EphA4 & Ephrin-A5 & EphA3 & Ephrin-A2 \\
\hline Posterior IX & A (lower), B, D & Absent & Homogeneous-EGL & A (higher), B, D \\
& Figs. 4, 7, 9 & Fig. 4 & Figs. 4, 8 & Figs. 4, 7 \\
V III $^{a}$ & A (Lm-Hl), B, D & C, E & Homogeneous-EGL & A (Hm-L1), B, D \\
& Figs. 4, 7, 9 & Fig. 4, 6 & Figs. 4, 8 & Figs. 4G, 7D \\
Central VI, VII & M, A (lateral), B (Hm-Lc-Hl), D & A $^{b}$ (medial), C, E & A (medial), B, D (low) & M, A (medial), B (Lm-Hc-Hl), D \\
& Figs. 4, 6, 7, 9 & Figs. 4C, 6C & Figs. 4, 8 & Figs. 4, 7 \\
Anterior I-V & M, A (lateral), B (medial), D & A (medial), & Absent (stops at lobule V) & M, A (lateral), B (medial)
\end{tabular}

Figs. 4, 6, 7

B (lateral), C

Figs. 4, 6
Fig. 4

Figs. 4, 7

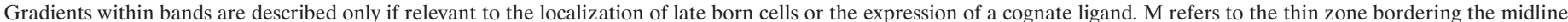
in band A (Fig. 4B, midline asterisk). EGL, external granule layer; Hm, high medial, Hl, high lateral, Lc, low central, Lm, low medial, Ll, low lateral.

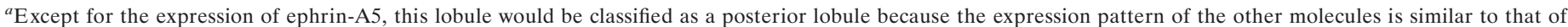
lobule IX.

${ }^{b}$ The expression of ephrin-A5 in band A of lobule VII is uncertain.
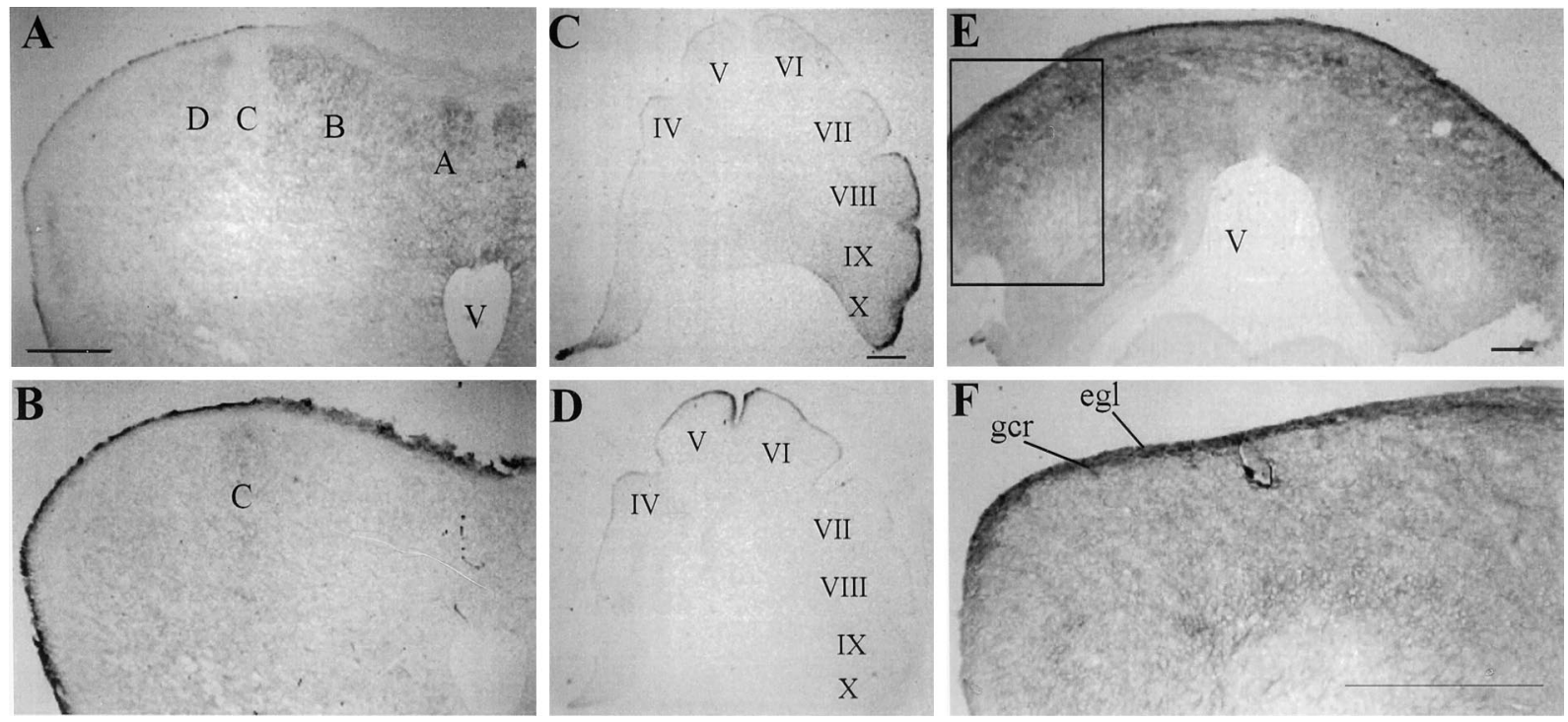

Figure 8. $A-D$, Immunostaining on coronal $(A, B)$ and sagittal $(C, D)$ adjacent frozen sections of EphA3 $(A, C)$ and ephrin-A5 $(B, D)$ at stage $37($ E11). Complementary expression is observed in Purkinje cell domains in lobule VII $(A, B)$ and in the external granule cell layer along the anterior-posterior axis $(C, D) . E, F$, EphA3 immunostaining in a coronal section taken from lobule IX of a stage 37 (E11) chick cerebellum. $F$, High magnification of inset in $E$. egl, External granule cell layer; gcr, granule cell ribbon; $V$, ventricle. $A, B, C, D$, and $E$ refer to Purkinje cell compartments labeled alphabetically from the midline. Roman numerals refer to cerebellar lobules. Scale bar, $200 \mu \mathrm{m}$.

Using a combination of molecular markers, Ozol et al. (1999) demonstrated that the mouse vermis is subdivided into four transverse zones: anterior (lobules I-V), central (lobules VI-VII), posterior (lobules VIII-IX), and nodular (lobule X). These authors suggested that the parasagittal compartments develop individually within each zone (Ozol et al., 1999). Our data are generally consistent with this conclusion, because transitions in the pattern of expression of individual Ephs and ephrins usually occur at positions corresponding to the proposed boundaries between zones (Fig. 4, Table 1).

\section{Restriction of the early phase of granule cell migration to ribbons at compartment boundaries}

We have demonstrated that the receptor EphB2 and ligand ephrin-B1 are expressed on migrating granule cells within ribbons (Fig. 10D-I). Expression is transient and restricted to cells that are migrating or poised to migrate. Neither EphB2 nor ephrin-B1 is expressed in the superficial portion of the external granular layer, which contains proliferating granule cell precursors. Expression of EphB2 and ephrin-B1 begins precisely as the granule cells enter the deeper portion of the external granular layer, where they become staged for migration (Fig. 10E,H) (Pasquale et al., 1992). The expression ceases as soon as the migrating cell ribbons penetrate the Purkinje cell layer and enter the internal granular layer. This behavior suggests that EphB2 and ephrin-B1 interaction may function to control the tangential migration of cells within the premigratory zone (Ryder and Cepko, 1994) and/or the ribboned migration of granule cells.

Either repulsive or attractive interactions mediated by EphB2/ ephrin-B1 interactions among granule cell precursors might plausibly contribute to guiding their migration or simply provide a cue to migrate, without specifying direction. Also, repulsive interactions between ephrin-B1 on granule cells and EphA4 on Purkinje cells might constrain granule cell migration to the boundaries between Purkinje cell compartments. This scenario is plausible because signaling is bi-directional for B class ephrins. Although the ephrins were initially characterized as receptor-activating ligands, ephrins of the B class are capable of mediating signal transduction, and this signaling is stimulated by interaction with Eph receptors (Henkemeyer et al., 1996; Holland et al., 1996; Bruckner et al., 1997; Stein et al., 1998; Mellitzer et al., 1999). In this context, ephrins are receptors, and Ephs are ligands. It has been reported that mammalian ephrin-B1 does not bind with EphA4 in vitro (Gale 

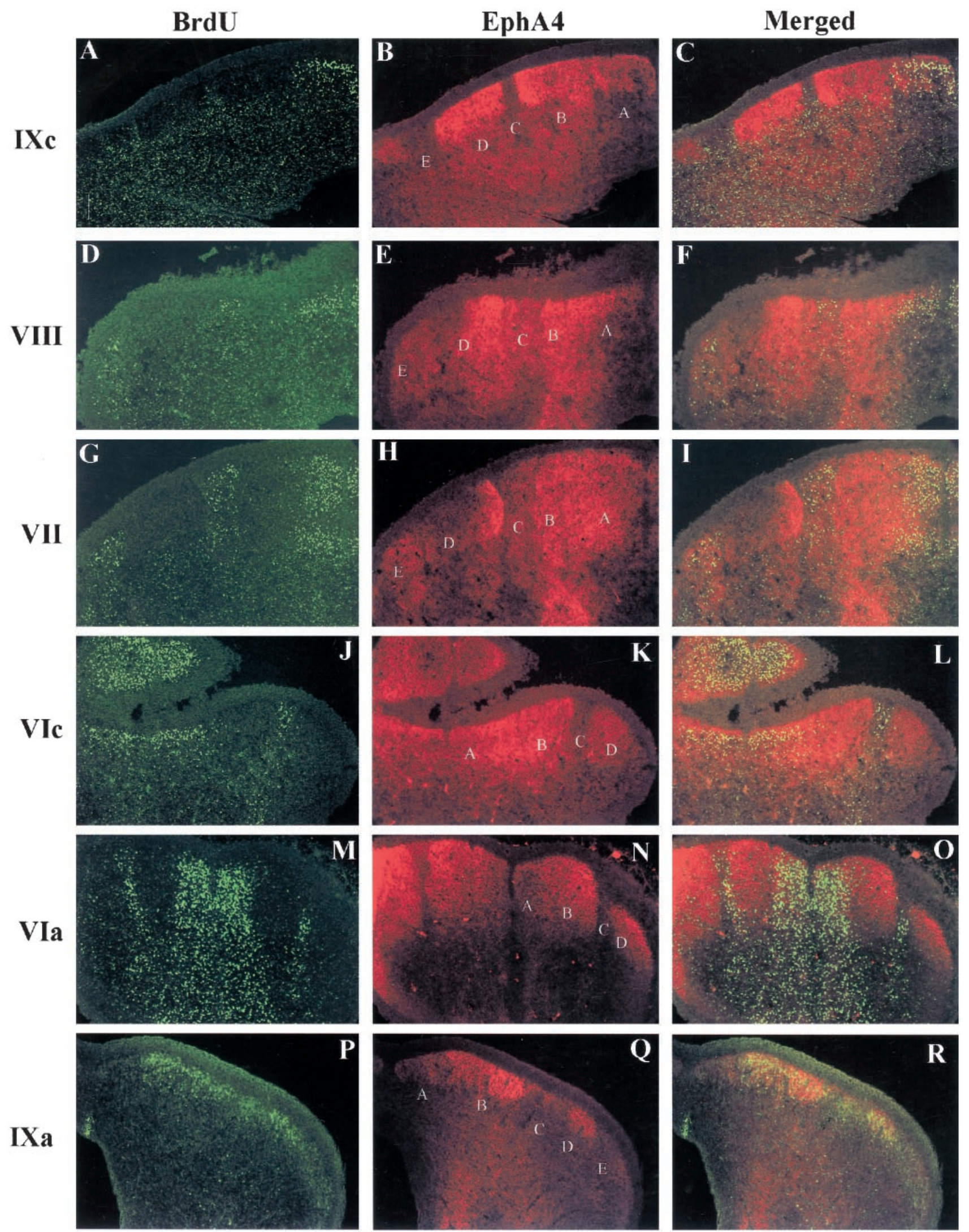

Figure 9. Double immunostaining of EphA4 (red in $B, C, E, F, H, I, K, L, N$, and $O$ ) and BrdU ( green in $A, C, D, F, G, I, J, L, M$, and $O$ ) in coronal plane of frozen sections of a stage 37 (E11) cerebellum that was pulsed with BrdU on E5. In all lobules, late-born cells colocalize to the EphA4 negative band, $C, E$, and to band $A$ (or medial portion of band $A$ ) where a lower level of EphA4 immunostaining is detected (see Results). For technical reasons (see Material and Methods, BrdU labeling), lower EphA4 expression in band $A$ of lobule VII is obscured in $H$ and is better observed in a $20 \mu \mathrm{m}$ adjacent section in Figure 7H. $P-R$, Double immunostaining of EphA4 (red in $Q$ and $R$ ) and BrdU ( green in $P$ and $R$ ) on E11 chick cerebellum that was pulsed with BrdU on E3. Early-born cells colocalize with EphA4-positive bands. $A, B, C, D$, and $E$ refer to Purkinje cell bands labeled alphabetically from the midline. Roman numerals refer to cerebellar lobules. Scale bar, $100 \mu \mathrm{m}$. 

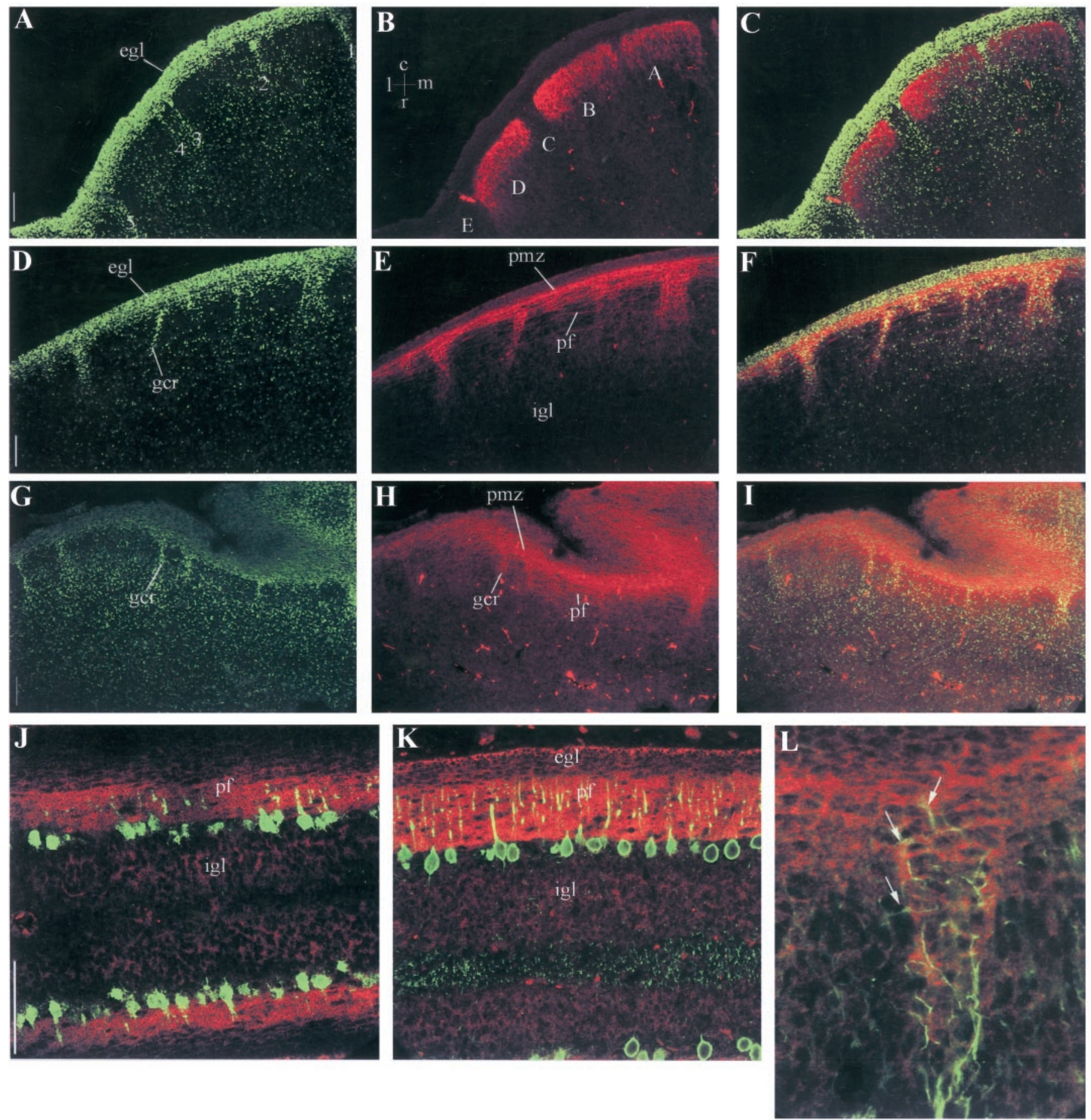

Figure 10. Double immunostaining of the granule cell marker Pax6 (green in $A, C, D, F, G$, and $I$ ) with EphA4 (red in $B$ and $C$ ) or ephrin-B1 (red in $E$ and $F$ ) or EphB2 (red in $H$ and $I$ ) in the coronal plane of a frozen section of a stage 39 (E13) cerebellum. $A-C$, Granule cells (arabic numerals in $A$ ) migrate as ribbons at the boundaries of EphA4 Purkinje cell bands (labeled alphabetically from the midline). D-I, From E9 to E14, both the EphB2 receptor and its ligand eprhin-B1 are expressed on the premigratory zone $(\mathrm{pmz})$ of the external granular layer (egl), the migrating granule cell ribbons $(g c r)$, and the parallel fibers $(p f)$. L, Double immunostaining of ephrin-B1 (red) and the glial marker vimentin (green) showing a lack of colocalization between the two. Arrows in $L$ point to glial cell bodies. $J, K$, Double immunostaining of the Purkinje cell marker, calbindin ( green), with either eprhin-B1 (red in $J$ ) or EphB2 (red in $K$ ) at E17. By E15, both EphB2 and ephrin-B1 expression appear localized to the parallel fibers, and a lower level of expression is observed in the internal granule cell layer. $g c r$, Granule cell raphe; igl, internal granule cell layer; $p f$, parallel fibers; $p m z$, premigratory zone of the external granule cell layer. Scale bar, $100 \mu \mathrm{m}$.

et al., 1996). However, immunoprecipitation experiments with chick ephrin-B1-Fc showed binding to chick EphA4, albeit weaker than with ephrin-A5 (E. B. Pasquale, unpublished observations). In lobules VIII-IX, where granule cell precursors also express EphA3 (Figs. $7 A, 8 E$ ), interactions between these receptors and ephrin-A2 on Purkinje cells also may constrain granule cell migration to the boundaries between Purkinje cell compartments.

\section{Axonal guidance}

Several studies have demonstrated a role for the Eph gene family in axonal pathfinding and the formation of topographic maps (for review, see Frisen and Barbacid, 1997; Pasquale, 1997; Zhou, 1997). The expression of various Ephs and ephrins on virtually every element of cerebellar circuitry is consistent with broad roles 
Table 2. Comparison of banding patterns of EphA4, ephrin-A5, and ephrin-A2 with other published molecules during the middle period

\begin{tabular}{llll} 
& EphA4 & Ephrin-A5 & Ephrin-A2 \\
\hline En-2 ${ }^{a}$ & & & Similar \\
En-1 & & \\
Shh $^{a}$ & Similar (bands A-D) & & \\
Gli2 $/ 4^{a}$ & Similar & Similar & \\
Cadherin $6 \mathrm{~B}^{b}$ & Similar & &
\end{tabular}

This comparison is limited to the posterior/central lobes of the chick cerebellum.

${ }^{a}$ Lin and Cepko (1999).

${ }^{b}$ Arndt et al. (1998).

of these molecules in the establishment of that circuitry. The output of the cerebellar cortex is organized in a pattern of parallel longitudinal zones, with Purkinje cell zones projecting to a particular cerebellar target nucleus (for review, see Voogd and Glickstein, 1998). Within the anterior lobe, EphA4 and ephrin-A2 are expressed in opposing gradients in the medial deep cerebellar nuclei (Fig. $7 P-R$ ) (data not shown). The heterogeneous distribution of ephrin-A2 may influence the pattern of innervation by various Purkinje cell compartments. Subnuclei of the inferior olive project to particular Purkinje cell zones. A zonal- and lobulespecific pattern of mossy fiber termination also has been described (Voogd and Glickstein, 1998). In the chick brainstem, we observed EphA4 expression in several nuclei that project afferents to the cerebellum, including the pontine, trigeminal, vestibular, and inferior olivary nuclei (data not shown). We also observed EphA4 expression in the ventral cerebellar commissure (Fig. $7 Q$ ), where most mossy axons enter and cross the cerebellum. Thus, the Ephephrin system may contribute to patterning of these projections also. Finally, the coexpression of EphB2 and ephrin-B1 on the axonal extensions of the granule cells, the parallel fibers, during the middle period of cerebellar development is suggestive of a role for these molecules in axonal outgrowth (Fig. 10D-K).

In summary, the pattern of expression of various Eph and ephrin proteins in the developing cerebellum suggests that these molecules play multiple roles in governing the development of the complex compartmental cerebellar organization. Further experiments will be required to elucidate the functional significance and regulatory mechanisms of the Eph-ephrin systems in cerebellar development.

\section{REFERENCES}

Altman J, Bayer SA (1995) Atlas of prenatal rat brain development. Boca Raton, FL: CRC

Alvarez Otero R, Sotelo C, Alvarado-Mallart RM (1993) Chick/quail chimeras with partial cerebellar grafts: an analysis of the origin and migration of cerebellar cells. J Comp Neurol 333:597-615.

Arndt K, Redies C (1998) Development of cadherin-defined parasagittal subdivisions in the embryonic chicken cerebellum. J Comp Neurol 401:367-381.

Arndt K, Nakagawa S, Takeichi M, Redies C 1998 Cadherin-defined segments and parasagittal cell ribbons in the developing chicken cerebellum. Mol Cell Neurosci 10:211-228.

Baader SL, Schilling ML, Rosengarten B, Pretsch W, Teutsch HF, Oberdick J, Schilling K (1996) Purkinje cell lineage and the topographic organization of the cerebellar cortex: a view from $\mathrm{X}$ inactivation mosaics. Dev Biol 174:393-406.

Baader SL, Vogel MW, Sanlioglu S, Zhang X, Oberdick J (1999) Selective disruption of "late onset" sagittal banding patterns by ectopic expression of engrailed-2 in cerebellar Purkinje cells. J Neurosci 19:5370-5379.

Bruckner K, Pasquale EB, Klein R (1997) Tyrosine phosphorylation of transmembrane ligands for Eph receptors. Science 275:1640-1643.

Chedotal A, Pourquie O, Ezan F, San Clemente H, Sotelo C (1996) BEN as a presumptive target recognition molecule during the development of the olivocerebellar system. J Neurosci 16:3296-3310.

Cheng HJ, Flanagan JG (1994) Identification and cloning of ELF-1, a developmentally expressed ligand for the Mek4 and Sek receptor tyrosine kinases. Cell 79:157-168.

Connor RJ, Menzel P, Pasquale EB (1998) Expression and tyrosine phosphorylation of Eph receptors suggest multiple mechanisms in patterning of the visual system. Dev Biol 193:21-35.

Durbin L, Brennan C, Shiomi K, Cooke J, Barrios A, Shanmugalingam S,
Guthrie B, Lindberg R, Holder N (1998) Eph signaling is required for segmentation and differentiation of the somites. Genes Dev 12:3096-3109.

Durbin L, Sordino P, Barrios A, Gering M, Thisse C, Thisse B, Brennan C, Green A, Wilson S, Holder N (2000) Anteroposterior patterning is required within segments for somite boundary formation in developing zebrafish. Development 127:1703-1713.

Feirabend HK (1990) Development of the longitudinal patterns in the cerebellum of the chicken (gallus domesticus): a cytoarchitectural study on the genesis of cerebellar modules. Eur J Morphol 28:169-223.

Feirabend HK, van Luxemburg EA, van Denderen-van Dorp H, Voogd J (1985) A tritiated thymidine autoradiographic study of the development of the cerebellum of the White Leghorn (gallus domesticus): "evidence for longitudinal neuroblast generation patterns." Acta Morphol NeerlScand 23:115-126.

Flanagan JG, Vanderhaeghen P (1998) The ephrins and Eph receptors in neural development. Annu Rev Neurosci 21:309-345.

Frisen J, Barbacid M (1997) Genetic analysis of the role of Eph receptors in the development of the mammalian nervous system. Cell Tissue Res 290:209-215.

Gale NW, Holland SJ, Valenzuela DM, Flenniken A, Pan L, Ryan TE, Henkemeyer M, Strebhardt K, Hirai H, Wilkinson DG, Pawson T, Davis S, Yancopoulos GD (1996) Eph receptors and ligands comprise two major specificity subclasses and are reciprocally compartmentalized during embryogenesis. Neuron 17:9-19.

Hamburger V, Hamilton HL (1951) A series of normal stages in the development of the chick embryo. J Exp Morphol 87:163-174.

Hawkes R, Mascher C (1995) The development of molecular compartmentation in the cerebellar cortex. Acta Anat (Basel) 151:139-149.

Hawkes R, Faulkner-Jones B, Tam P, Tan SS (1998) Pattern formation in the cerebellum of murine embryonic stem cell chimeras. Eur J Neurosci 10:790-793.

Henkemeyer M, Orioli D, Henderson JT, Saxton TM, Roder J, Pawson T, Klein R (1996) Nuk controls pathfinding of commissural axons in the mammalian central nervous system. Cell 86:35-46.

Herrup K, Kuemerle B (1997) The compartmentalization of the cerebellum. Annu Rev Neurosci 20:61-90.

Holash JA, Pasquale EB (1995) Polarized expression of the receptor protein tyrosine kinase Cek5 in the developing avian visual system. Dev Biol 172:683-693.

Holland SJ, Gale NW, Mbamalu G, Yancopoulos GD, Henkemeyer M, Pawson T (1996) Bidirectional signalling through the EPH-family receptor Nuk and its transmembrane ligands. Nature 383:722-725.

Hornberger MR, Dutting D, Ciossek T, Yamada T, Handwerker C, Lang S, Weth F, Huf J, Wessel R, Logan C, Tanaka H, Drescher U (1999) Modulation of EphA receptor function by coexpressed ephrinA ligands on retinal ganglion cell axons. Neuron 22:731-742.

Kanemitsu A, Kobayashi Y (1988) Time of origin of Purkinje cells and neurons of the deep cerebellar nuclei of the chick embryo examined by 3H-thymidine autoradiography. Anat Anz 165:167-175.

Lin JC, Cepko CL (1998) Granule cell raphes and parasagittal domains of Purkinje cells: complementary patterns in the developing chick cerebellum. J Neurosci 18:9342-9353.

Lin JC, Cepko CL (1999) Biphasic dispersion of clones containing Purkinje cells and glia in the developing chick cerebellum. Dev Biol 211:177-197.

Logan C, Wizenmann A, Drescher U, Monschau B, Bonhoeffer F, Lumsden A (1996) Rostral optic tectum acquires caudal characteristics following ectopic engrailed expression. Curr Biol 6:1006-1014.

Martone ME, Holash JA, Bayardo A, Pasquale EB, Ellisman MH (1997) Immunolocalization of the receptor tyrosine kinase EphA4 in the adult rat central nervous system. Brain Res 771:238-250.

Mathis L, Bonnerot C, Puelles L, Nicolas JF (1997) Retrospective clonal analysis of the cerebellum using genetic laacZ/lacZ mouse mosaics. Development 124:4089-4104.

Mellitzer G, Xu Q, Wilkinson DG (1999) Eph receptors and ephrins restrict cell intermingling and communication. Nature 400:77-81.

Millen KJ, Wurst W, Herrup K, Joyner AL (1994) Abnormal embryonic cerebellar development and patterning of postnatal foliation in two mouse Engrailed-2 mutants. Development 120:695-706.

Millet S, Alvarado-Mallart RM (1995) Expression of the homeoboxcontaining gene En-2 during the development of the chick central nervous system. Eur J Neurosci 7:777-791.

Monschau B, Kremoser C, Ohta K, Tanaka H, Kaneko T, Yamada T, Handwerker C, Hornberger MR, Loschinger J, Pasquale EB, Siever DA, Verderame MF, Muller BK, Bonhoeffer F, Drescher U (1997) Shared and distinct functions of RAGS and ELF-1 in guiding retinal axons. EMBO J 16:1258-1267.

Oberdick J, Baader SL, Schilling K (1998) From zebra bands to postal zones: deciphering patterns of gene expression in the cerebellum. Trends Neurosci 21:383-390

Ozol K, Hawkes R (1997) Calbindin organization in the newborn mouse cerebellum: genealogical analysis of Purkinje cell compartments. Soc Neurosci Abstr 23:877.

Ozol K, Hayden JM, Oberdick J, Hawkes R (1999) Transverse zones in the vermis of the mouse cerebellum. J Comp Neurol 412:95-111.

Pasquale EB (1991) Identification of chicken embryo kinase 5, a develop- 
mentally regulated receptor-type tyrosine kinase of the Eph family. Cell Regul 2:523-534.

Pasquale EB (1997) The Eph family of receptors. Curr Opin Cell Biol 9:608-615.

Pasquale EB, Deerinck TJ, Singer SJ, Ellisman MH (1992) Cek5, a membrane receptor-type tyrosine kinase, is in neurons of the embryonic and postnatal avian brain. J Neurosci 12:3956-3967.

Rogers JH, Ciossek T, Menzel P, Pasquale EB (1999) Eph receptors and ephrins demarcate cerebellar lobules before and during their formation. Mech Dev 87:119-128.

Ryder EF, Cepko CL (1994) Migration patterns of clonally related granule cells and their progenitors in the developing chick cerebellum. Neuron 12:1011-1028.

Soans C, Holash JA, Pasquale EB (1994) Characterization of the expression of the Cek8 receptor-type tyrosine kinase during development and in tumor cell lines. Oncogene 9:3353-3361.

Stein E, Lane AA, Cerretti DP, Schoecklmann HO, Schroff AD, Van Etten RL, Daniel TO (1998) Eph receptors discriminate specific ligand oligomers to determine alternative signaling complexes, attachment, and assembly responses. Genes Dev 12:667-678.

Tanaka S, Ueda T, Nakajima K, Higashinakagawa T (1996) Replication patterns of repetitive DNA sequences on the $\mathrm{W}$ chromosome are altered during development of the chick embryo. Exp Cell Res 223:233-241.
Voogd J, Glickstein M (1998) The anatomy of the cerebellum. Trends Neurosci 21:370-375.

Voogd J, Jaarsma D, Marani E (1996) The cerebellum: chemoarchitecture and anatomy. In: Handbook of chemical neuroanatomy (Swanson, LW, Bjorklund A, Hokfelt T, eds), pp 1-575. New York: Elsevier.

Wagner J, Arenas E (1998) Ephrins regulate neurotrophin responsiveness in cerebellar granule neurons during development. Neurosci Abstr 24:1287.

Wingate RJ, Hatten ME (1999) The role of the rhombic lip in avian cerebellum development. Development 126:4395-4404.

Xu Q, Alldus G, Holder N, Wilkinson DG (1995) Expression of truncated Sek-1 receptor tyrosine kinase disrupts the segmental restriction of gene expression in the Xenopus and zebrafish hindbrain. Development 121:4005-4016.

Xu Q, Alldus G, Macdonald R, Wilkinson DG, Holder N (1996) Function of the Eph-related kinase rtk1 in patterning of the zebrafish forebrain. Nature 381:319-322.

Xu Q, Mellitzer G, Robinson V, Wilkinson DG (1999) In vivo cell sorting in complementary segmental domains mediated by Eph receptors and ephrins. Nature 399:267-271.

Zhou R (1997) Regulation of topographic projection by the Eph family receptor Bsk (EphA5) and its ligands. Cell Tissue Res 290:251-259. 